\title{
Prediction of Effective Elastic Modulus of Biphasic Composite Materials
}

\author{
Anupama Upadhyay, Ramvir Singh* \\ Heat Transfer Laboratory, Department of Physics, University of Rajasthan, Jaipur, India \\ Email: ${ }^{*}$ singhrvs@rediffmail.com
}

Received November 8, 2011; revised December 15, 2011; accepted December 25, 2011

\begin{abstract}
Two semi-empirical approaches for prediction of elastic modulus of biphasic composites have been proposed. Developed relations are for pore free matrix and pore free filler and found to depend on nonlinear contribution of volume fraction of constituents as well as ratio of elastic properties of individual phases. These relations are applied for the calculation of effective elastic modulus mainly for $\mathrm{Al}_{2} \mathrm{O}_{3}-\mathrm{NiAl}$, SiC-Al, Alumina-Zirconia, $\mathrm{Al}-\mathrm{Al}_{2} \mathrm{O}_{3}$, W-glass and Flax-Resin composite materials. Theoretical predictions using developed relations are compared with experimental data. It is found that the predicted values of effective elastic modulus using modified relations are quite close to the experimental results.
\end{abstract}

Keywords: Elastic Modulus; Composite Material; Matrix-Inclusion

\section{Introduction}

Composite materials have been intensively developed since the 1960 because these are leading classes of engineering materials due to their outstanding properties i.e. low weight in comparison with metals, high stiffness and strength as well as their high chemical resistance. Low cost fibers and resin materials have increased the use of composites in infrastructural applications such as buildings and bridges. Carbon and composite nano-tubes have exclusive structural, energetic and mechanical properties i.e. exceptional stiffness and higher Young's modulus, highly resistant etc. Thus it is desirable to calculate the effective elastic properties from the knowledge of the structure of the composite material. The effective elastic properties are one of the most important properties that determine the mechanical performance of a material. The problem of determining the effective mechanical and transport properties of a composite material with complex microstructures is a challenging task to engineers and scientists because of its fundamental and technological importance in almost every area of material science. This problem continues to be the focus of intense research, from design as well as theoretical point of view. Composites are widely being used in civil engineering and space vehicles/ sea vessels. Fiber reinforced composite material's elastic properties have been widely used in many structural applications varying from swimming pool diving board to advanced aerospace components.

The basic information required for the evaluation of

*Corresponding author. the effective moduli is the volume fractions, and elastic moduli, of each phase. Many previous theories for determination of elastic properties demonstrated that the mechanical and elastic properties depend on the adhesion between the phases, the geometrical setup of their constituent and the technological process employed for obtaining them. The theoretical approaches discussed in the literature for estimating the effective elastic modulus are based on the effective medium theories, which provide approximate approximations by homogenizing the complex medium. Many empirical parameters have been introduced into the models to account for the influence of the structure variations on the results. The simplest theoretical approaches to predict the elastic modulus of two phase material are the classical averaging schemes $[1,2]$. A common approximation for the effective moduli is the self-consistent method (SCM) of Hill [3] and Budiansky [4] which involves solving the equations of elasticity for a spherical particle of phase 1 surrounded by a medium of unknown effective moduli. Thus there have been several different approaches to study and approximate the elastic properties of composites. Yagi and Che [5] studied the effect of the shape and distribution of anisotropic ellipsoidal inhomogeneity on the overall elastic moduli of a composite material using the concept of local region from the view point of micromechanics. Molina et al. [6] employed an orthogonal tight binding model in their work. Lu [7] did most extensive theoretical study using an empirical pair potential model to estimate the Young's modulus, Poisson's ratio and other elastic constants of both single wall and multi wall nano tube and nano tube 
ropes. Lijma et al. [8] studied bending of nano tubes experimentally using simulation techniques. Treacy et al. [9] experimentally determined the Young's modulus of carbon multi wall nano tubes using thermal vibration analysis of cantilevered tubes by recording the force needed to bend anchored nanotubes. Chopra and Zetly [10] have also used thermal vibrational analysis for Young modulus of multiwall Boron Nitride nano tubes. Garshasbinia and Jame [11] studied the mechanical properties in laminated composite plates using genetic algorithm by an optimized search procedure. Genetic algorithm provides the additional technique of evaluating material properties from the measured natural frequencies. The theoretical approaches found in the literature for predicting the effective elastic properties by homogenizing the complex medium [12], an empirical parameter have been introduced for accounting the effect of structural variation on the results $[13,14]$.

Zhang et al. [15] proposed the random location of obstacles in constructing an artificial random microstructure. Some researchers have given upper and lower bounds, and derived theoretical relations and verified by experimental data $[16,17]$. Synder et al. [13] gave a method to generate randomly distributed circular inclusions, digital microtonographic information and statistical correlation functions have been adopted in reconstruction of the structures more accurately [17-19].Wang et al. [20] developed a simpler method the random generation growth method (RGG), inspired by the spirit of cluster growing theory [21]. Robarts and Garboczi [22] used finite element method to study the influence of porosity and pore shape on the elastic properties of models, porous ceramics and found Young's modulus and provided simple formula to predict elastic properties. Segurado and Llorca [23] developed a numerical approximation to the elastic properties of sphere reinforced composites. The elastic constants of the ensemble of spheres embedded in a continuous and isotropic elastic matrix were computed through the finite element analysis of the three-dimensional periodic unit cells, whose size was chosen as a compromise between the minimum size required to obtain accurate results in the statistical sense and the maximum one imposed by the computational cost.

Three types of materials were studied: rigid spheres; spherical voids in an elastic matrix and a typical composite made up of glass spheres in an epoxy resin. The moduli obtained for different unit cells showed very little scatter. Sahraoui and Mariez [24] studied the linear elastic properties of anisotropic open-cell foams to examine the elasticity of these kinds of porous materials through their microstructure. Warren and Kraynik [25] presented a theoretical model for the introduction of the linear elastic properties of open-cell foams. They considered threedimensional open-cell foams in a tetrahedral unit cell and derived a model for effective elastic constants, under the assumption that all possible orientations of the unit cell are equally probable in a representative volume element. The elastic constants are sensitive to the composition change. Ceramics have different bonding characteristics from those of metal. When ceramic is added or mixed into metal or vice-versa then heterogeneous interface is developed. That is why the elastic properties of the two phase materials generally deviate from the prediction calculated by using the rule of mixtures. These composite materials are very useful since their individual properties (i.e. of ceramics and metals) are different but effective properties of the composite demonstrate many significant applications in industry. Composites combine the properties of two or more components; toughness of $\mathrm{Al}_{2} \mathrm{O}_{3}$ is improved by the addition of $\mathrm{NiAl}$ [26]. Thermal stability is improved by adding $\mathrm{Al}$ into $\mathrm{SiC}$ [27]. We need the elastic properties of two phase systems for designing new composites and application based materials.

In this paper elastic moduli are calculated for several composites using two exclusively different semi empirical approaches having dependence on volume fraction and elastic modulus of constituent phases and compared with experimental values. Experimental data given in Tables 3 on the elastic properties of several composite materials are taken from the literature. The experimental data cover $\mathrm{Al}_{2} \mathrm{O}_{3}-\mathrm{NiAl}[26,28]$ only limited part of the composition range for a certain composite. Here in our considered examples $\mathrm{Al}_{2} \mathrm{O}_{3}-\mathrm{NiAl}$ covers whole range of the compositions [29].

\section{Theoretical Formulation}

Voigt [1] proposed the effective elastic modulus of the composite as

$$
E=E_{1} v_{1}+E_{2} v_{2}
$$

with $v_{1}+v_{2}=1$. This mixing rule is for the iso-strain state. This model assumes the constituents of a composite to be in parallel arrangement subjected to the same strain. For the condition of isostress, Reuss [2] proposed a formula for the effective elastic modulus as

$$
E=\frac{E_{1} E_{2}}{E_{1} v_{2}+E_{2} v_{1}}
$$

where

$E_{1}$ : Elastic modulus of Filler;

$E_{2}$ : Elastic modulus of Matrix;

$v_{1}$ : Volume fraction of Filler;

$v_{2}$ : Volume fraction of Matrix.

But Hill [30] explained that for real materials, none of the iso-stress or iso-strain assumption is realistic. The tractions at interface are not at equilibrium under the Voigt condition and the interface cannot be considered under the Reuss condition. Though the equality in Equation (1) 
is true only when the Poisson's Ratio of the two phases is the same.

Considering the dependence of elastic modulus on the ratio of elastic modulus of individual phases, the formula for the effective elastic modulus of composite material, composed of two phases (matrix and filler), is proposed as

$$
E_{e f f}=E_{s}^{n} E_{p}^{1-n}
$$

where

$$
\begin{gathered}
E_{s}=E_{1} v_{1}+E_{2} v_{2} \\
E_{p}=\frac{E_{1} E_{2}}{E_{1} v_{2}+E_{2} v_{1}}
\end{gathered}
$$

Equation (3) is solved for $n$ in terms of $E_{s}, E_{p}$ and $E_{\text {eff }}$. The solution is

$$
n=\frac{\ln \left[\frac{v_{1}}{E_{1}} E_{\text {eff }}+\frac{\left(1-v_{1}\right)}{E_{2}} E_{\text {eff }}\right]}{\ln \left[1+v_{1}\left(1-v_{1}\right)\left(\frac{E_{1}}{E_{2}}+\frac{E_{2}}{E_{1}}-2\right)\right]}
$$

Here

$$
v_{1}+v_{2}=1
$$

Here we see from Equation (6) that $n$ is a function of $v_{1}$, $E_{1}$ and $E_{2}$ respectively, so relation between $n, v_{1}, E_{1}$ and $E_{2}$ is obtained using curve fitting technique as:

$$
n=A x^{4}+B x^{3}+C x^{2}+D x+E
$$

where

$$
x=v_{1}^{1 / 3} \ln \frac{E_{2}}{E_{1}}
$$

and $A, B, C, D$ and $E$ are constants, having different values for different composite materials. Values of these constants for respective samples (composite materials) are given in Table 1. Thus we can calculate the effective Elastic modulus for a composite material from Equation (3), using the values of $E_{s}$ and $E_{p}$ and the value of $n$ for particular composite material calculated from Equation (8).

We calculated the values of $n$ for many samples using Equation (8) to obtain theoretical value of effective elastic modulus and compared with the experimental results for respective samples. Comparison is shown in graphs (Figure 1 to Figure 6).

We also propose another semi-empirical relation to calculate effective elastic modulus having linear dependence on elastic modulus $E_{1}$ and $E_{2}$ respectively. Proposed formula is given as:

$$
E_{\text {eff }}=E_{2}+K\left(\frac{v_{1}}{v_{2}}\right) E_{1}
$$

Here

$$
v_{1}+v_{2}=1
$$

Table 1. Values of constants $A, B$ and $C$ for different composite samples.

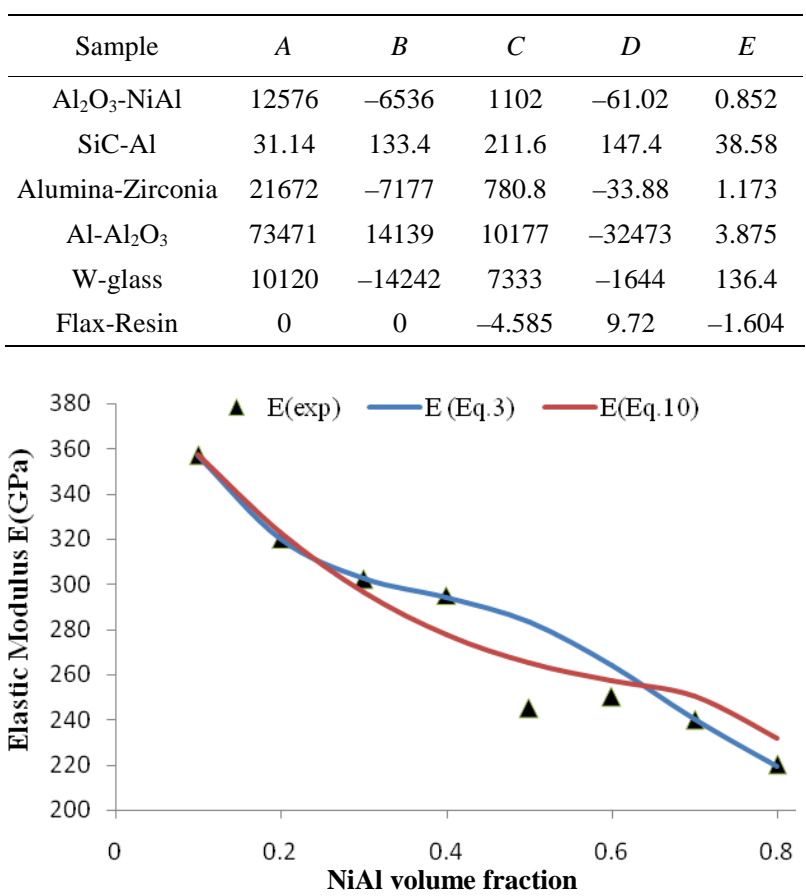

Figure 1. Elastic Modulus of $\mathrm{Al}_{2} \mathrm{O}_{3}-\mathrm{NiAl}$ composite as a function of NiAl content.

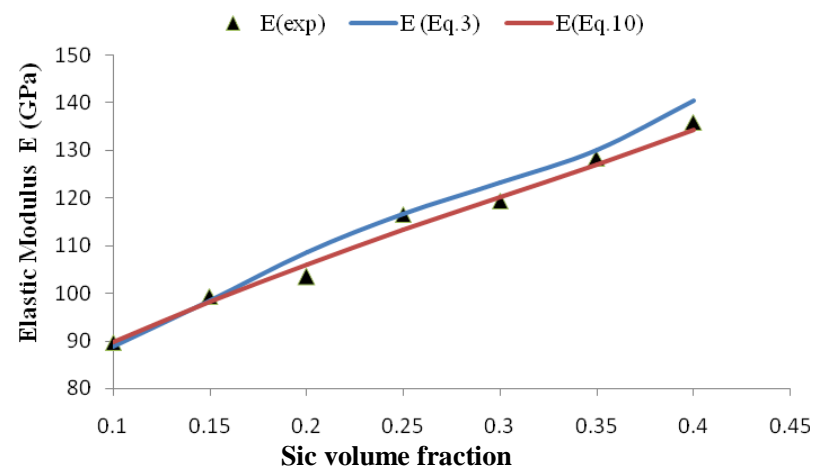

Figure 2. Elastic Modulus of SiC-Al composite as a function of $\mathrm{SiC}$ content.

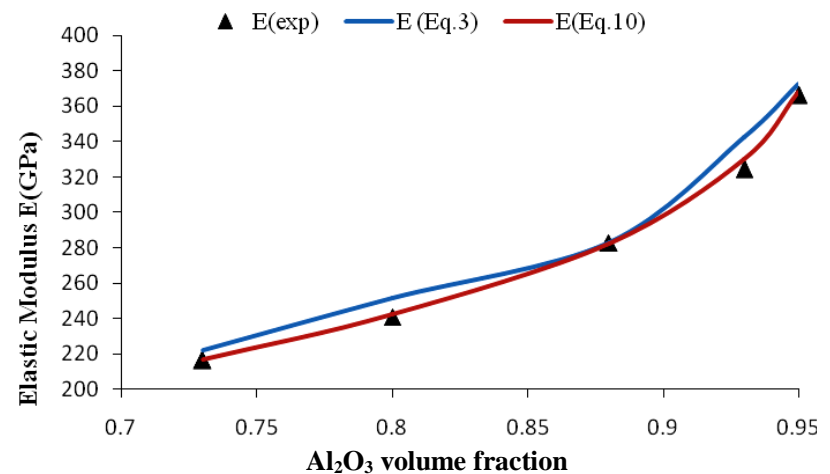

Figure 3. Elastic Modulus of $\mathrm{Al}_{2} \mathrm{O}_{3}-\mathrm{ZrO}_{2}$ composite as a function of $\mathrm{ZrO}_{2}$ content. 


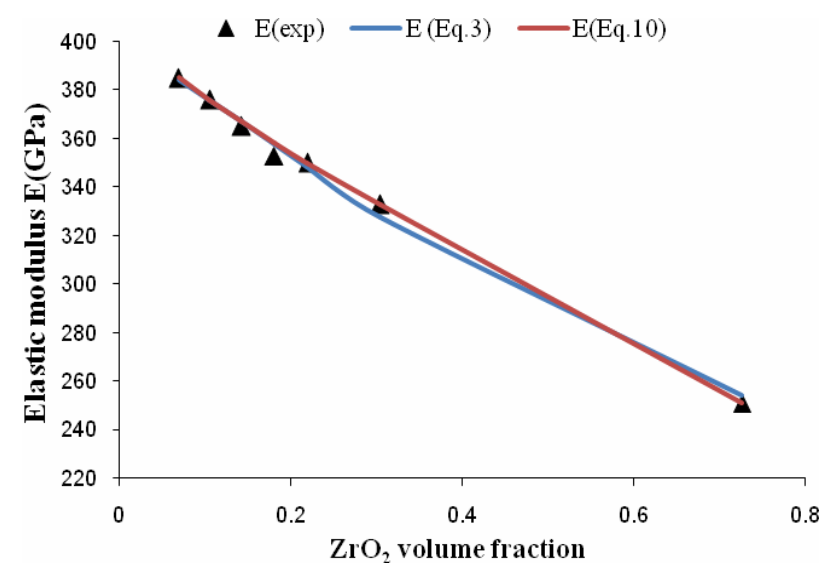

Figure 4. Elastic Modulus of $\mathrm{Al}-\mathrm{Al}_{2} \mathrm{O}_{3}$ composite as a function of $\mathrm{Al}_{2} \mathrm{O}_{3}$ content.

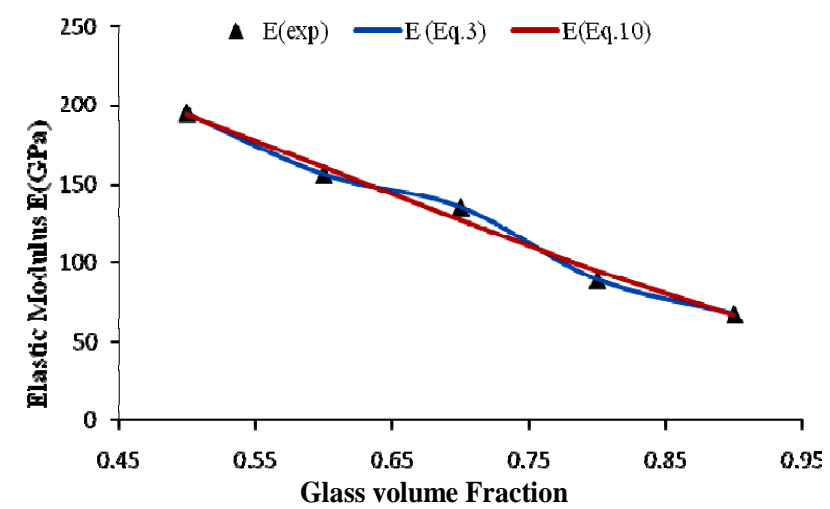

Figure 5. Elastic Modulus of W-glass composite as a function of Glass content.

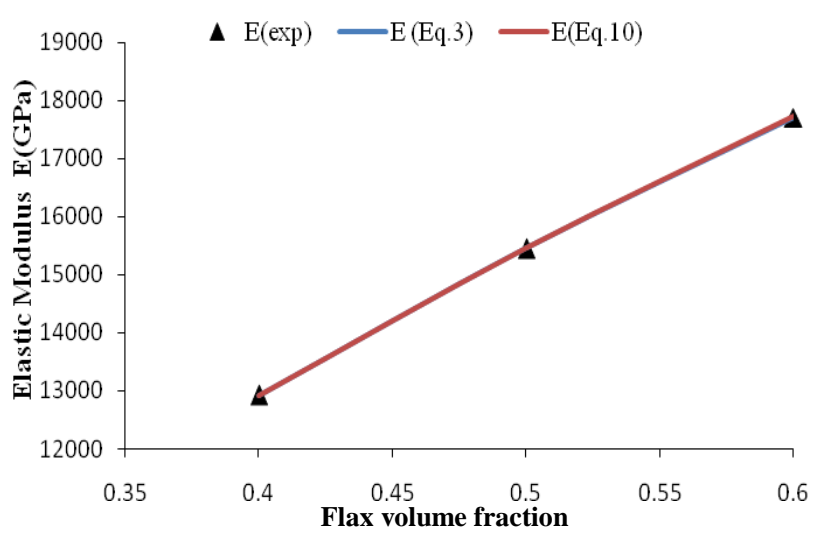

Figure 6. Elastic Modulus of Flax-Resin composite as a function of Flax content.

and

$E_{1}$ : Elastic modulus of Filler;

$E_{2}$ : Elastic modulus of Matrix;

$v_{1}$ : Volume fraction of Filler;

$v_{2}$ : Volume fraction of Matrix and constant term $K$ is written in term of volume fraction of filler phase as

$$
K=L x^{2}+M x+N
$$

where

$$
x=v_{1}^{1 / 3} \ln \frac{E_{2}}{E_{1}}
$$

$L, M$ and $N$ in Equation (12) are constants, having different values for different composite materials. Values of these constants for respective samples (composite materials) are given in Table 2 . We have calculated the value of $K$ for respective samples using values of constants $L$, $M$ and $N$ given in Table 2. Using these values of $K$ in Equation.10, we can obtain the value of effective elastic modulus for various composite materials at different filler concentrations. Apart from the data of $\mathrm{Al}_{2} \mathrm{O}_{3}-\mathrm{NiAl}$ system, the available data for other ceramic-metal composites, SiC-Al, glass-W and Alumina-Zirconia, $\mathrm{Al}-\mathrm{Al}_{2} \mathrm{O}_{3}$ Flax-Resin, are also compared in the present study to verify our model predictions.

\section{Results and Discussion}

Particulate composite like $\mathrm{Al}_{2} \mathrm{O}_{3}-\mathrm{NiAl}$, SiC-Al were prepared by using the conventional powder processing technique which show little dependence on orientation and the elastic constants are determined either by static methods such as the measurements of longitudinal deformation or by dynamic method, such as the method applying by ultrasonic waves. The static methods usually determine only elastic modulus due to the difficulties involved in the measurement of the transverse strain [31]

The Voigt-Reuss model treats a laminated system. Each phase in the system is separated by another layer but actually composites are treated as composed of continuous matrix and isolated phase. For example in SiC-Al composite the SiC particles are not sintered together in the SiC-Al composite. In another example in $\mathrm{Al}_{2} \mathrm{O}_{3}-\mathrm{NiAl}$ both phases are continuous [29]. These two phases form an interpenetrating microstructure which is quite different from SiC-Al. Interface of the $\mathrm{Al}_{2} \mathrm{O}_{3}$ - $\mathrm{NiAl}$ composite is relatively weak and the $\mathrm{Al}_{2} \mathrm{O}_{3}-\mathrm{NiAl}$ system is sintered at its solid state [28]. As any load is applied on the composite in the presence of weakly bonded isolated particles, the load is mainly sustained by the matrix alone. The strains along and perpendicular to the loading direction thus close to those of matrix alone. The existence of the

Table 2. Values of constants $L, M$ and $N$ for different composite samples.

\begin{tabular}{cccc}
\hline Sample & $L$ & $M$ & $N$ \\
\hline $\mathrm{Al}_{2} \mathrm{O}_{3}$-NiAl & -36.99 & 18.79 & -2.521 \\
$\mathrm{SiC}-\mathrm{Al}$ & 1.912 & 1.57 & 0.486 \\
Alumina-Zirconia & 8.753 & 3.884 & -1.08 \\
$\mathrm{Al}^{-\mathrm{Al}_{2} \mathrm{O}_{3}}$ & -0.747 & 0.06 & 0.298 \\
$\mathrm{~W}$-glass & 1.582 & 6.969 & -3.796 \\
Flax-Resin & -14.58 & 36.24 & -23.73 \\
\hline
\end{tabular}


Table 3. Predicted Elastic Modulus in comparison with experimental values.

\begin{tabular}{|c|c|c|c|c|c|c|}
\hline \multicolumn{7}{|c|}{ a) $\mathbf{A l}_{2} \mathbf{O}_{3}-\mathrm{NiAl} E_{1}(\mathrm{NiAl})=186 \mathrm{GPa}, E_{2}\left(\mathrm{Al}_{2} \mathrm{O}_{3}\right)=400 \mathrm{GPa}[26,29]$} \\
\hline S. No. & $v_{1}$ & $E_{\text {eff }}$ (Equation (3)) GPa & $E_{\text {eff }}$ Equation.(10)) GPa & $\mathrm{E}(\exp ) \mathrm{GPa}$ & \%Deviation (Equation (3)) & $\begin{array}{c}\text { \%Deviation (Equation } \\
(10) \text { ) }\end{array}$ \\
\hline 1 & 0.1 & 356.97 & 357.31 & 357 & 0.007 & 0.087 \\
\hline 2 & 0.2 & 319.86 & 322.89 & 320 & 0.042 & 0.904 \\
\hline 3 & 0.3 & 302.42 & 296.44 & 302 & -0.139 & -1.839 \\
\hline 4 & 0.4 & 294.26 & 277.46 & 295 & 0.249 & -5.944 \\
\hline 5 & 0.5 & 283.24 & 265.01 & 245 & -15.609 & 8.188 \\
\hline 6 & 0.6 & 264.01 & 257.44 & 250 & -5.607 & 2.977 \\
\hline 7 & 0.7 & 240.22 & 250.42 & 240 & -0.094 & 4.345 \\
\hline 8 & 0.8 & 219.46 & 231.47 & 220 & 0.243 & 5.216 \\
\hline
\end{tabular}

b) $\mathrm{SiC}-\mathrm{Al} E_{1}(\mathrm{SiC})=450 \mathrm{GPa}, E_{2}(\mathrm{Al})=70 \mathrm{GPa}[32,33]$

\begin{tabular}{ccccccc}
\hline S. No. & $v_{1}$ & $E_{\text {eff }}$ Equation (3)) GPa & $E_{\text {eff }}$ Equation (10)) GPa & E(exp) GPa & \%Deviation (Equation (3)) & $\begin{array}{c}\text { \%Deviation (Equation } \\
(10))\end{array}$ \\
\hline 1 & 0.1 & 88.72 & 89.79 & 89.7 & 1.085 & 0.110 \\
2 & 0.15 & 98.44 & 98.30 & 99.36 & 0.919 & -1.057 \\
3 & 0.2 & 108.63 & 106.07 & 103.5 & -4.957 & 2.487 \\
4 & 0.25 & 116.70 & 113.27 & 116.61 & -0.080 & -2.856 \\
5 & 0.3 & 123.12 & 120.15 & 119.37 & -3.144 & 0.657 \\
6 & 0.35 & 130.07 & 127.01 & 128.34 & -1.35 & -1.036 \\
7. & 0.4 & 140.56 & 134.25 & 135.93 & -3.408 & -1.234
\end{tabular}

c) $\mathrm{Al}_{2} \mathbf{O}_{3}$-Zirconia $E_{1}$ (Zirconia) $=210 \mathrm{GPa}, E_{2}\left(\mathrm{Al}_{2} \mathrm{O}_{3}\right)=400 \mathrm{GPa}$ [34]

\begin{tabular}{ccccccc}
\hline S. No. & $v_{1}$ & $E_{\text {eff }}$ Equation (3)) GPa & $E_{\text {eff }}$ Equation (10)) GPa & E(exp) GPa & \%Deviation (Equation (3)) & $\begin{array}{c}\text { \%Deviation (Equation } \\
(10))\end{array}$ \\
\hline 1 & 0.069 & 384.99 & 384.11 & 385 & 0.0003 & -0.229 \\
2 & 0.105 & 375.99 & 375.65 & 376 & 0.0002 & -0.090 \\
3 & 0.142 & 366.99 & 366.86 & 365 & -0.547 & 0.510 \\
4 & 0.18 & 358.31 & 357.73 & 353 & -1.505 & 1.342 \\
5 & 0.219 & 350.00 & 348.30 & 350 & -0.0003 & -0.485 \\
6 & 0.304 & 333.00 & 327.62 & 333 & -0.001 & -1.614 \\
7 & 0.726 & 251.04 & 254.48 & 251 & -0.017 & 1.388
\end{tabular}

d) $\mathrm{Al}-\mathrm{Al}_{2} \mathbf{O}_{3} E_{1}\left(\mathrm{Al}_{2} \mathrm{O}_{3}\right)=390 \mathrm{GPa}, E_{2}(\mathrm{Al})=69 \mathrm{GPa}$ [35]

\begin{tabular}{ccccccc}
\hline S. No. & $v_{1}$ & $E_{\text {eff }}$ Equation (3)) GPa & $E_{\text {eff }}($ Equation (10)) GPa & E(exp) GPa & \%Deviation (Equation (3)) & $\begin{array}{c}\text { \%Deviation (Equation } \\
(10))\end{array}$ \\
\hline 1 & 0.73 & 222.20 & 216.64 & 216.4 & -2.680 & 0.113 \\
2 & 0.8 & 251.52 & 242.04 & 241 & -4.360 & 0.435 \\
3 & 0.88 & 283.01 & 282.62 & 282.8 & -0.070 & -0.063 \\
4 & 0.93 & 342.48 & 330.28 & 324.4 & -5.570 & 1.813 \\
5 & 0.95 & 372.62 & 368.15 & 366.4 & -1.690 & 0.478
\end{tabular}

e) W-Glass $E_{1}($ Glass $)=81 \mathrm{GPa}, E_{2}(\mathrm{~W})=355 \mathrm{GPa}[32,36]$

\begin{tabular}{ccccccc}
\hline S. No. & $v_{1}$ & $E_{\text {eff }}$ (Equation (3)) GPa & $E_{\text {eff }}($ Equation (10)) GPa & E(exp) GPa & \%Deviation (Equation (3)) & $\begin{array}{c}\text { \%Deviation (Equation } \\
(10))\end{array}$ \\
\hline 1 & 0.5 & 194.80 & 194.31 & 195.25 & 0.226 & -0.477 \\
2 & 0.6 & 156.32 & 160.81 & 156.2 & -0.079 & 2.952 \\
3 & 0.7 & 135.42 & 127.23 & 134.9 & -0.390 & -5.680 \\
4 & 0.8 & 89.30 & 94.41 & 88.75 & -0.625 & 6.388 \\
5 & 0.9 & 67.86 & 66.49 & 67.45 & -0.615 & -1.411
\end{tabular}

f) Flax-Resin $E_{1}($ Flax $)=4500 \mathrm{GPa}, E_{2}($ Resin $)=28000 \mathrm{GPa}$ [37]

\begin{tabular}{ccccccc}
\hline S. No. & $v_{1}$ & $E_{\text {eff }}$ (Equation (3)) GPa & $E_{\text {eff }}$ (Equation (8)) GPa & E(exp) GPa & \%Deviation (Equation (3)) & $\begin{array}{c}\text { \%Deviation (Equation } \\
(10))\end{array}$ \\
\hline 1 & 0.4 & 12918.11 & 12922.6 & 12917 & -0.008 & -0.043 \\
2 & 0.5 & 15451.71 & 15462.53 & 15451 & -0.004 & -0.074 \\
3 & 0.6 & 17709.05 & 17733.59 & 17709 & -0.0003 & -0.138 \\
\hline
\end{tabular}


second phase affects little to the strain of the matrix. When an interpenetrating microstructure is formed by the two phases one phase is closely constrained by the other one though they do not bond strongly together. The elastic behavior of matrix is thus affected by the presence of interpenetrating second phase. Alumina particles were well dispersed and well bonded to the matrix. Here we ignored the effect of porosity Thus these formulas can estimate the elastic modulus for non-porous materials only. Our proposed formula suits well for pore free matrix and pore free filler. With the knowledge of the correlation between the elastic moduli and porosity for a particular ceramic product we can determine elastic modulus of matrix with pore too. Since several investigations in literature show that Young's modulus decreases as porosity increases. By introducing porosity and porosity correction factor which takes account of geometrical variables such as pore size, shape and location. Only those composite materials which have considerable amount of porosity may show deviation between experimental data and predictions that is too due to presence of third phase air.

The values of effective elastic modulus obtained by the proposed approaches (Equations (3) and (10)) are compared with experimental values of Elastic modulus for different composites $\left(\mathrm{Al}_{2} \mathrm{O}_{3}-\mathrm{NiAl}\right.$, SiC-Al, AluminaZir-conia, $\mathrm{Al}-\mathrm{Al}_{2} \mathrm{O}_{3}$, W-glass and Flax-Resin). The basic properties of each phase in these composites are also shown in Table 2. The model predictions proposed in the present study cover most of the experimental data. The experimental data of the composites are close to the predictions made by our proposed formula. One may note that the Elastic modulus shows strong dependence on $E_{2} / E_{1}$, less dependence on $v_{1} / v_{2}$. This comparison for all composites is shown in Table 3 and in Figures 1-6.

Our proposed predictions seem good on comparison but still some error is there due to the presence of air pores. Since we have neglected the pore effect and considered the pore free matrix. References are given in the respect- tive tables for the source of experimental data.

Results obtained from our proposed formula show good matching with the experimental values. Still a small difference is seen with the measured data. It may be due to relative arbitrariness of data selection. Thus our relations provide a satisfactory prediction in terms of the volume fraction variations.

\section{Conclusion}

The comparison between experimental data and proposed models predictions is made in the present study. It shows some dependence on the micro structural characteristics of ceramic metal composites. The interconnectivity of each phase in a composite and the bonding characteris- tics of interface may also affect the elastic modulus of composite. The elastic properties of the composite materials depend strongly on elastic properties of individual phases, and their concentration in a composite. This dependence is studied using two quite different semi-empirical approaches. In the first approach modified form of series and parallel combination is proposed to calculate effective elastic modulus, while as in second approach, we consider linear dependence of effective elastic modulus on elastic properties of the constituents and their respective volume fractions respectively. Seven composites $\left(\mathrm{Al}_{2} \mathrm{O}_{3}-\mathrm{NiAl}\right.$, SiC-Al, Alumina-Zirconia, $\mathrm{Al}-\mathrm{Al}_{2} \mathrm{O}_{3}, \mathrm{~W}-$ glass and Flax-Resin) are used for comparison to validate the modified relations. The calculated values of elastic modulus using both the theoretical predictions are in good agreement with the experimental values for all composite materials. The suggested theoretical results offer good approximation for elastic modulus.

\section{Acknowledgements}

A Junior Research fellowship awarded by CSIR-UGC to one of the authors (AU) is gratefully acknowledged.

\section{REFERENCES}

[1] W. Voigt, "Ueber die Beziehung Zwischen den Beiden Elasticitätsconstanten Isotroper Körper,” Annalen der Physik, Vol. 274, No. 12, 1889, pp. 573-587. doi:10.1002/andp.18892741206

[2] A. Reuss and Z. Angrew, "Berechnung der Fließgrenze von Mischkristallen auf Grund der Plastizit tsbedingung für Einkristalle ,” ZAMM-Journal of Applied Mathematics and Mechanics, Vol. 9, No. 1, 1929, pp. 49-58.

[3] R. Hill, "A Self-Consistent Mechanics of Composite Materials," Journal of the Mechanics and Physics of Solids, Vol. 13, No. 4, 1965, pp. 213-222. doi:10.1016/0022-5096(65)90010-4

[4] B. Budiansky, "On the Elastic Moduli of Some Heterogeneous Materials," Journal of the Mechanics and Physics of Solids, Vol. 13, 1965, pp. 223-227. doi:10.1016/0022-5096(65)90011-6

[5] K. Yagi and L. Che, "Elastic Properties of Composite Material with Anisotropic Ellipsoidal Inhomogeneities,” Proceedings of the Fifteenth International Offshore and Polar Engineering Conference, 19-24 June 2005, Seoul, pp. 551-556.

[6] J. M. Molina, S. S. Savinsky and N. V. Khokhriakov, “A Tight Binding Model for Calculations of Structures and Properties of Graphite Nanotubes," Journal of Chemical Physics, Vol. 104, No. 12, 1996, p. 4652. doi:10.1063/1.471211

[7] J. P. Lu, "Elastic Properties of Carbon Nanotubes and Nanoropes,” Physical Review Letters, Vol. 79, No. 7, 1997, pp. 1297-1300. doi:10.1103/PhysRevLett.79.1297

[8] S. Lijima, C. Brabec, A. Maiti and J. Bernhole, "Structural 
Flexibility of Carbon Nanotubes,” Journal of Chemical Physics, Vol. 104, No. 5, 1996, p. 2089. doi:10.1063/1.470966

[9] M. M. J. Treacy, T. W. Ebbeson and J. M. Gibson, “Exceptionally High Young's Modulus Observed for Individual Carbon Nanotubes Nature," Nature, Letters to Nature, Vol. 381, 1996, pp. 678-680. doi:10.1038/381678a0

[10] N. G. Chopra and A. Zettl, "Measurement of the Elastic Modulus of a Multiwall Boron Nitride Nanotube,” Solid State Communications, Vol. 105, No. 5, 1998, pp. 297-300. doi:10.1016/S0038-1098(97)10125-9

[11] N. Garshashbinia and J. E. Jam, "Properties in Laminated Composite Plates Using Genetic Algorithm,” Indian Polymer Journal, Vol. 14, No. 1, 2005, pp. 39-46.

[12] J. P. Watt, G. F. Davies and R. J. Cnnel, "Elastic Properties of Composite Materials,” Reviews of Geophysics, Vol. 14, No .4, 1976, pp. 541-563. doi:10.1029/RG014i004p00541

[13] K. A. Snyder, E. J. Garboczi and A. R. Day, “The Elastic Modulii of Simple Two Dimensional Isotropic Composites, Computer Simulation and Effective Medium Theory,” Journal of Applied Physics, Vol. 72, No. 12, 1992, pp. 5948-5955. doi:10.1063/1.351903

[14] M. T. Tilbrook and M. Hottman, "On the Mechanical Properties of Alumina Epoxy Composites with an Inter Penetrating Network Structure," Materials Science and Engineering: A, Vol. 393, No. 1-2, 2005, pp. 170-178. doi:10.1016/j.msea.2004.10.004

[15] H. F. Zhang, X. S. Ge and H. Ye, "Randomly Mixed Model for Predicting the Effective Thermal Conductivity of Moist Porous Media,” Journal of Physics D: Applied Physic, Vol. 39, No. 1, 2006, pp. 220-226. doi:10.1088/0022-3727/39/1/032

[16] Z. Hashin, "Analysis of Composite Materials-A Survey,” Journal of Applied Mechanics, Vol. 50, No. 3, 1983, pp. 481-505. doi:10.1115/1.3167081

[17] S. Torquato, "Random Heterogeneous Materials: Micro Structures and Macroscopic Properties," Applied Mechanics Reviews, Vol. 55, No. 4, 2002, p. B62. doi:10.1115/1.1483342

[18] N. Losic, J. F. Thovert and P. M. Adler, "Reconstruction of Porous Media with Multiple Solid Phases,” Journal of Colloid and Interface Science, Vol. 186, No. 2, 1997, pp. 420-433. doi:10.1006/jcis.1996.4659

[19] D. S. Li, G. Saheli, M. Khaleel and H. Mgarinestani, "Quantitative Prediction of Effective Conductivity in Anisotropic Heterogeneous Media Using Two Point Correlation Functions," Computational Materials Science, Vol. 38, No. 1, 2006, pp. 45-50. doi:10.1016/j.commatsci.2006.01.004

[20] M. Wang, J. K. Wang, N. N. Pan and S. Y. Chen, "Mesoscopic Predictions of the Effective Thermal Conductivity of Micro Scale Random Porous Media,” Physical Review E, Vol. 75, No. 3, 2007, pp. 260-265.

[21] P. Meakin, "Fractals, Scaling and Growth Far from Equilibrium,” Cambridge University Press, Cambridge, 1998.

[22] P. A. Roberts and E. J. Garboczi, "Elastic Properties of
Model Porous Ceramics," Journal of the American Ceramic Society, Vol. 83, No. 12, 2000, pp. 3041-3048. doi:10.1111/j.1151-2916.2000.tb01680.x

[23] J. Segurado and J. Llorca, “A Numerical Approximation to the Elastic Properties of Sphere-Reinforced Composites,” Journal of the Mechanics and Physics of Solids, Vol. 50, No. 10, 2002, pp. 2107-2121. doi:10.1016/S0022-5096(02)00021-2

[24] S. Sahraoui, E. Mariez and M. Etchessahar, "Linear Elastic Properties of Anisotropic Open-Cell Foams,” Journal of the Acoustical Society of America, Vol. 110, No. 1, 2001, pp. 635-637. doi:10.1121/1.1378351

[25] W. E. Warren and A. M. Kraynik, "The Linear Elastic Properties of Open-Cell Foams," Journal of Applied Mechanics, Vol. 55, No. 2, 1988, pp. 341-346. doi:10.1115/1.3173680

[26] W. H. Tuan, Y. P. Pai, "Mechanical Properties of $\mathrm{Al}_{2} \mathrm{O}_{3}$ Nial Composites," Journal of the American Ceramic Society, Vol. 82, No. 6, 1999, pp. 1624-1626. doi:10.1111/j.1151-2916.1999.tb01974.X

[27] M. F. Ashby, "Criteria for Selecting the Components of Composites,” Acta Metallurgica et Materialia, Vol. 41, No. 5, 1993, pp. 1313-1335. doi:10.1016/0956-7151(93)90242-K

[28] W. H. Tuan, W. B. Chou, H. C. You and S. T. Chang, "The Effects of Microstructure on the Mechanical Properties of $\mathrm{Al}_{2} \mathrm{O}_{3}$-Nial Composites," Materials Chemistry and Physics, Vol. 56, No. 2, 1998, p.157. doi:10.1016/S0254-0584(98)00168-0

[29] C. L. Hsieh, W. H. Tuan and T. T. Wu, "Elastic Behavior of a Model Two-Phase Material," Journal of the European Ceramic Society, Vol. 24, No. 15-16, 2004, pp. 37893793. doi:10.1016/j.jeurceramsoc.2004.02.002

[30] R. Hill, "Elastic Properties of Reinforced Solids: Some Theoretical Principles," Journal of the Mechanics and Physics of Solids, Vol. 11, No. 5, 1963, pp. 357-372. doi:10.1016/0022-5096(63)90036-X

[31] W. Koster and H. Franz, "Poisson's Ratio for Metals and Alloys,” Metallurgical Review, Vol. 6, No. 21, 1961, pp. 1-56.

[32] C. L. Hsieh, W. H. Tuan and T. T. Wu, "Elastic Properties of Ceramic-Metal Particulate Composite,” Material Science and Engineering A, Vol. 393, 2005, pp. 133-139.

[33] L. C. Davis, J. Chen and M. F. Thorpe, "Predicting the Elastic Properties of Composite Materials," Proceedings of the American Society for Composites - 7th Technical Conference, Pennsylvania, 13-15 October 1992, pp. 339-348.

[34] W. Pabst, G. Ticha, E. Gregorova and E. Tynova, "Effective Elastic Properties of Alumina-Zirconia Composite Ceramics, Part-5 Tensile Modulus of Alumina-Zirconia Composite Ceramics,” Ceramics Silikaty, Vol. 49, No. 2, 2005, pp. 77-85.

[35] M. Wang and N. Pan, "Elastic Property of Multiphase Composites with Random Microstructures," Journal of Computational Physics, Vol. 228, No. 16, 2009, pp. 59785988. doi:10.1016/j.jcp.2009.05.007

[36] D. P. H. Hasselman and R. M. Fulrath, "Effect of Spherical Tungsten Dispersions on Young's Modulus of a 
Glass,” Journal of the American Ceramic Society, Vol. 48, No. 10, 1965, pp. 548-549.

doi:10.1111/j.1151-2916.1965.tb14668.x

[37] D. Bolcu, G. Stanescu and M. Ursache, “Theoretical and
Experimental Study on Determination of the Elastic Properties for Composite Materials," Romanian Reports in Physics, Vol. 56, No. 1, 2004, pp. 3-12. 